\title{
Intercellular calcium signaling in a gap junction-coupled cell network establishes asymmetric neuronal fates in $C$. elegans
}

\author{
Jennifer A. Schumacher ${ }^{1}$, Yi-Wen Hsieh${ }^{1}$, Shiuhwei Chen², Jennifer K. Pirri ${ }^{3}$, Mark J. Alkema ${ }^{3}$, Wen-Hong Li \\ Chieh Chang ${ }^{1, *, \pm}$ and Chiou-Fen Chuang ${ }^{1, *, \neq}$
}

\begin{abstract}
SUMMARY
The C. elegans left and right AWC olfactory neurons specify asymmetric subtypes, one default AWC ${ }^{\mathrm{OFF}}$ and one induced AWC ${ }^{\mathrm{ON}}$, through a stochastic, coordinated cell signaling event. Intercellular communication between AWCs and non-AWC neurons via a NSY5 gap junction network coordinates AWC asymmetry. However, the nature of intercellular signaling across the network and how individual non-AWC cells in the network influence AWC asymmetry is not known. Here, we demonstrate that intercellular calcium signaling through the NSY-5 gap junction neural network coordinates a precise 1 AWC ${ }^{\mathrm{ON}} / 1$ AWC ${ }^{\mathrm{OFF}}$ decision. We show that NSY-5 gap junctions in C. elegans cells mediate small molecule passage. We expressed vertebrate calcium-buffer proteins in groups of cells in the network to reduce intracellular calcium levels, thereby disrupting intercellular communication. We find that calcium in non-AWC cells of the network promotes the AWC ${ }^{\mathrm{ON}}$ fate, in contrast to the autonomous role of calcium in AWCs to promote the AWC ${ }^{\mathrm{OFF}}$ fate. In addition, calcium in specific non-AWCs promotes AWC ${ }^{\mathrm{N}}$ side biases through NSY-5 gap junctions. Our results suggest a novel model in which calcium has dual roles within the NSY-5 network: autonomously promoting AWC ${ }^{\text {OFF }}$ and non-autonomously promoting $\mathrm{AWC}^{\mathrm{ON}}$.
\end{abstract}

KEY WORDS: Gap junctions, Calcium signaling, Stochastic left-right neuronal asymmetry, C. elegans

\section{INTRODUCTION}

Many cell types communicate through gap junctions during embryonic development to regulate cell-fate determination, proliferation and morphogenesis (Levin, 2007). Gap junctions form intercellular channels that assemble from head-to-head docking of hemichannels, one provided by each of two contacting cells (Bennett and Zukin, 2004). Each hemichannel consists of subunits called connexins and pannexins in vertebrates, and innexins in invertebrates. Gap junction-mediated intercellular communication allows rapid and direct transfer of small molecules and ions across a field of cells without the need for specialized ligands and receptors. Gap junction-mediated calcium waves divide the mammalian neocortex into distinct neuronal domains (Yuste et al., 1995; Bennett and Zukin, 2004). Spontaneous gap junction-dependent calcium waves are also observed in the developing retina (Kandler and Katz, 1998). In addition, gap junction communication through movement of serotonin contributes to orienting the left-right body axis in both frog and avian models (Fukumoto et al., 2005a; Fukumoto et al., 2005b; Levin et al., 2006). Importantly, most studies that defined roles for gap junctions in development relied on broad loss-offunction or inhibition of individual subunits, or global inhibition of molecules that are predicted to pass through gap junctions. Therefore, the roles that individual cells within gap junction

\footnotetext{
'Division of Developmental Biology, Children's Hospital Medical Center Research Foundation, 240 Albert Sabin Way, Cincinnati, OH 45229, USA. ${ }^{2}$ Department of Cell Biology and Biochemistry, University of Texas Southwestern Medical Center at Dallas, 5323 Harry Hines Blvd., Dallas, TX 75390, USA. ${ }^{3}$ Department of Neurobiology, LRB 717, University of Massachusetts Medical School, 364 Plantation Street, Worcester, MA 01605, USA.

*These authors contributed equally to this work

${ }^{\ddagger}$ Authors for correspondence (chiou-fen.chuang@cchmc.org;

chieh.chang@cchmc.org)
}

Accepted 17 August 2012 networks may play in vivo to drive cell-fate determination or other patterning events are almost completely unknown.

We showed previously that the innexin nsy-5 (inx-19WormBase) is required for asymmetric differentiation of the $C$. elegans AWC olfactory neuron pair (Chuang et al., 2007). The left and right AWC neurons are morphologically symmetric (White et al., 1986), but express different genes to convey the ability to sense different chemicals (Pierce-Shimomura et al., 2001; Wes and Bargmann, 2001). The two AWC neurons communicate through Notch-independent signaling during late embryogenesis to generate asymmetric cell fates: induced $\mathrm{AWC}^{\mathrm{ON}}$, which expresses the reporter gene str-2p::GFP, and default $\mathrm{AWC}^{\mathrm{OFF}}$, which does not (Troemel et al., 1999; Chuang and Bargmann, 2005). Each wildtype animal generates one $\mathrm{AWC}^{\mathrm{ON}}$ and one $\mathrm{AWC} \mathrm{OFF}^{\mathrm{O}} ; 50 \%$ of the animals induce $\mathrm{AWC}^{\mathrm{ON}}$ on the left whereas the other $50 \%$ induce $\mathrm{AWC}^{\mathrm{ON}}$ on the right (Troemel et al., 1999). The default $\mathrm{AWC} \mathrm{OFF}^{\mathrm{O}}$ fate is executed by the cell-autonomous activity of a calcium/calmodulin-dependent protein kinase II (CaMKII) and mitogen-activated protein kinase (MAPK) cascade (Sagasti et al., 2001; Chuang and Bargmann, 2005). NSY-5 gap junctions and NSY-4 claudins function in parallel to induce $\mathrm{AWC}^{\mathrm{ON}}$ by inhibiting the CaMKII cascade (VanHoven et al., 2006; Chuang et al., 2007).

$n s y-5$ is expressed during embryogenesis in both AWC neurons and in at least 17 pairs of other neurons (Chuang et al., 2007) (supplementary material Fig. S1). nsy-5-dependent gap junctions transiently connect AWCs and adjacent neurons in embryos. $n s y-5$ functions primarily autonomously in AWCs to promote AWC ${ }^{\mathrm{ON}}$ fate. However, $n s y-5$ activity in ASH, AWB and AFD neurons promotes or inhibits $\mathrm{AWC}^{\mathrm{ON}}$ (Chuang et al., 2007). These results suggest that individual neighboring neurons in the NSY-5 network, which is defined by the 18 pairs of $n s y$-5-expressing neurons that are likely to be linked by gap junctions (Taylor et al., 2010), communicate with each other and with AWCs to fine-tune the signaling that establishes precise AWC asymmetry. However, the nature of intercellular signaling across the NSY-5 network and how 
individual non-AWCs in the network influence AWC asymmetry is not known.

Components of the voltage-gated calcium channel (the poreforming $\alpha 1$ subunit UNC-2 and the regulatory $\alpha 2 \delta$ subunit UNC36) are also required upstream of CaMKII for communication between $\mathrm{AWC}$ to ensure a precise $1 \mathrm{AWC} / \mathrm{ON} / 1 \mathrm{AWC} \mathrm{OFF}^{\mathrm{OF}}$ decision (Bauer Huang et al., 2007). This leads to the hypothesis that intercellular calcium signaling, through NSY-5, mediates communication between AWCs and non-AWCs, and that changes in calcium levels in neurons that are coupled with AWCs through NSY-5 influence AWC fate choice. Here, we develop a unique system to address the roles of specific cells within the NSY-5 network in AWC asymmetry by using cell type-specific expression of calcium-buffering proteins. We show that calcium in non-AWCs of the NSY-5 network is required for the induction of $1 \mathrm{AWC}^{\mathrm{ON}} / 1 \mathrm{AWC} \mathrm{CFF}^{\mathrm{OF}}$ asymmetry. In addition, calcium in $\mathrm{AWB}$ and $\mathrm{ASH}$ neurons confers different side biases of $\mathrm{AWC}^{\mathrm{ON}}$ induction. Our results support a model in which calcium within the NSY-5 network has dual roles in establishing AWC asymmetry: autonomous promotion of $\mathrm{AWC}^{\mathrm{OFF}}$ and non-autonomous promotion of $\mathrm{AWC}^{\mathrm{ON}}$.

\section{MATERIALS AND METHODS}

\section{C. elegans strains}

Wild-type strains were C. elegans variety Bristol, strain N2. Strains were generated and maintained using standard methods (Brenner, 1974). Integrated transgenic lines and mutations used in these experiments included: kyIs 140 [str-2p::GFP; lin-15(+)] I (Troemel et al., 1999), nsy5(ky634) I (Chuang et al., 2007), lfe-2(sy326) I, kyIs323 [str-2p::GFP; ofm-1p::GFP] II, plc-3(tm1340) II, tph-1 (mg280) II, unc-36(e251) III, itr1(sy331) IV, itr-1(sy290) IV, itr-1(sy291) IV, itr-1(sy327) IV, itr-1(sy328) $I V, n s y-4(k y 627)$ IV (VanHoven et al., 2006), unc-43(n498gf) IV, eri1 (mg366) IV, unc-76(e911) V, unc-2(e55) X, unc-2(zf35gf) X, lin-15b(n744) $X$, ipp-5(sy605) X, kyls136 [str-2p::GFP; lin-15(+)] X, vyIs18 [nsy5p::mCherry-nsy-5 3'].

Transgenes maintained as extrachromosomal arrays included: $v y E x 498$, 499 [odr-3p::calbindin D28K; odr-1p::DsRed; ofm-1p::DsRed], vyEx699, 700 [odr-3p::parvalbumin; odr-1p::DsRed; ofm-1p::DsRed], vyEx1066, 1068, 1069 [odr-3p::calbindin D9K; odr-1p::DsRed; ofm-1p::DsRed], vyEx567, 571 [nsy-5p::calbindin D28K; odr-1p::DsRed; ofm-1p::DsRed], $v y E x 724, \quad 725,726$ [nsy-5p::parvalbumin; odr-1p::DsRed; ofm1p::DsRed], vyEx1063 [odr-3p::cmd-1; odr-1p::DsRed; ofm-1p ::DsRed], vyEx484 [nsy-5p::calbindin D28K::mCherry; ofm-1p::DsRed], vyEx992, 993, 994, 997 [odr-3p::rParv; odr-1p::DsRed; ofm-1p::DsRed], vyEx990, 991, 996 [odr-3p::rParvCDEF/AV; odr-1p::DsRed; ofm-1p::DsRed], vyEx521, 522 [str-1p::calbindin D28K; odr-1p::DsRed; ofm-1p::DsRed], vyEx562, 564 [sra-6p::calbindin D28K::SL2::mCherry; ofm-1p::DsRed], vyEx568, 569, 570 [str-1p::nsy-5IR::SL2::mCherry; ofm-1p::DsRed], vyEx1320, 1321 [str-1p::mCherry; ofm-1p::DsRed], vyEx1322, 1323 [sra6p::SL2::mCherry; ofm-1p::DsRed].

\section{Plasmid construction and germline transformation}

M. musculus calbindin D28K cDNA from pCMV6-calbindin-28K (Origene) was subcloned to make nsy-5p::calbindin D28K, odr3p::calbindin D28K, nsy-5p:calbindin D28K::mCherry, str-1p::calbindin D28K and sra-6p::calbindin D28K::SL2::mCherry. M. musculus parvalbumin cDNA from pCMV6-parvalbumin (Origene) was subcloned to make odr-3p::parvalbumin and nsy-5p::parvalbumin. Calbindin D9K cDNA was synthesized from mixed embryonic day (E) 14.5 and postnatal day (P) 0 mouse brain total RNA and subcloned to make odr-3p::calbindin $D 9 K$. cmd-1 cDNA was obtained by RT-PCR from L1 stage worms and subcloned to make odr-3p::cmd-1. odr-3p::rParvCDEF/AV was constructed using the Quikchange II XL Kit (Stratagene). The original construct, rat ParvCDEF, contains four substitutions that replace the first (D51A, D90A) and last (E62V, E101V) charged amino acids of the two EF-hand domains responsible for calcium binding (Pauls et al., 1994; John et al., 2001). We mutated the remaining charged amino acids in the second EF hand domain (K92V, D93A, D95A, K97V and E100V). To make $n s y-$ $5 I R$, antisense and sense transcripts of $n s y-5$ were inserted upstream and downstream, respectively, of an 888-bp linker sequence as previously described (Chuang and Meyerowitz, 2000). This construct was subcloned

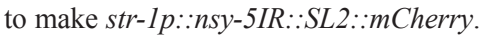

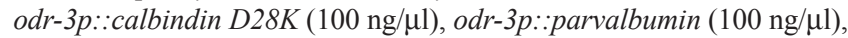

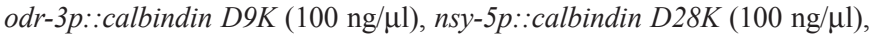

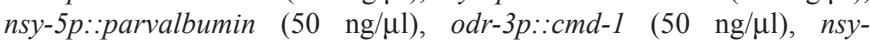

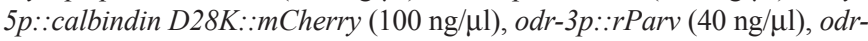
3p::rParvCDEF/AV (40 ng/ $\mu \mathrm{l})$, str-1p::calbindin D28K (100 $\mathrm{ng} / \mu \mathrm{l})$, sra-6p::calbindin D28K::SL2::mCherry (100 $\mathrm{ng} / \mu \mathrm{l})$, str-1p::nsy-

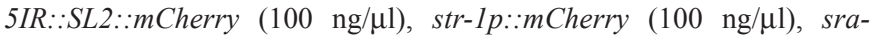
$6 p:: S L 2:: m$ Cherry $(100 \mathrm{ng} / \mu \mathrm{l})$, odr-1p::DsRed $(15 \mathrm{ng} / \mu \mathrm{l})$ and $\mathrm{ofm}$ $1 p:: D s R e d(30 \mathrm{ng} / \mu 1)$ were injected into animals as previously described (Mello and Fire, 1995).

\section{Chemotaxis assays}

Chemotaxis assays were performed as previously described (Bargmann et al., 1993). Odors were diluted in ethanol and tested at standard concentrations (1:1000 for butanone and 1:10,000 for 2,3-pentanedione). About 50-200 animals were assayed for each strain and each odor in each individual assay. All assays were performed four independent times. Relative chemotaxis index was calculated by dividing each absolute chemotaxis index by the highest wild-type chemotaxis index observed for each odor for each independent trial.

\section{C. elegans primary cell culture}

Cells were isolated from C. elegans embryos as previously described (Christensen et al., 2002) and resuspended to a final concentration of 3-7 $\times 10^{6}$ cells $/ \mathrm{ml}$. For dye transfer assays, cells were cultured in rotating eppendorf tubes for $24-48$ hours at $22^{\circ} \mathrm{C}$ prior to assays. For calcium imaging, cells were seeded on $25-\mathrm{mm}$ round cover glasses coated with 0.5 $\mathrm{mg} / \mathrm{ml}$ peanut lectin (Sigma) and cultures were maintained for 21-72 hours at $22^{\circ} \mathrm{C}$ in a humidified chamber prior to imaging.

\section{Dye transfer assays}

C. elegans embryonic cells were washed twice with HBS (Gibco) containing $10 \mathrm{mM}$ HEPES (pH 7.35) and $5.5 \mathrm{mM}$ glucose, then loaded with $3 \mu \mathrm{M}$ NPE-HCCC2/AM (plus $0.015 \%$ puronic acid in $0.015 \%$ DMSO) for 45 minutes in the dark at $22^{\circ} \mathrm{C}$. Loaded cells were washed with HBS and seeded on $15-\mathrm{mm}$ slides that had been precoated with peanut lectin (Sigma), in 35-mm dishes (MatTek). Seeded cells were incubated in HBS for 15 minutes to allow complete hydrolysis of acetoxymethyl (AM) esters. Localized ultraviolet (UV) uncaging of NPE-HCCC2 and fluorescence imaging were performed on an inverted Zeiss Axiovert 200 with a Hamamatsu ORCA-ER cooled CCD camera and $100 \times$ oil immersion objective (NA 1.4) as previously described (Dakin et al., 2005). Images were acquired and analyzed with the Openlab integrated imaging software (Improvision). All of the five wild-type cell pairs that were analyzed showed dye transfer, whereas none of the five $n s y-5(l f)$ cell pairs assayed had dye transfer.

\section{Calcium imaging}

C. elegans embryonic cells were loaded with Fluo-4 calcium-indicator dye as previously described (Marsh, 1995). Briefly, cells were washed three times with physiological saline solution (PSS; $145 \mathrm{mM} \mathrm{NaCl}, 5 \mathrm{mM} \mathrm{KCl}$, $1 \mathrm{mM} \mathrm{MgSO} 4,10 \mathrm{mM}$ HEPES, pH 7.4, $10 \mathrm{mM}$ glucose, plus $2 \mathrm{mM}$ $\mathrm{CaCl}_{2}$ ), then loaded with $1.5 \mu \mathrm{M}$ Fluo- 4 , AM (plus $0.015 \%$ puronic acid in $0.015 \%$ DMSO) for 45 minutes in the dark at $22^{\circ} \mathrm{C}$. Cells were washed three times with PSS $\left(2 \mathrm{mM} \mathrm{CaCl}_{2}\right)$, then recovered in the final wash for 30-60 minutes in the dark. Ionomycin (in PSS plus $10 \mathrm{mM} \mathrm{CaCl}_{2}$ ) was added on top of cells to a final concentration of $10 \mu \mathrm{M}$. EGTA in PSS was added on top of cells to a final concentration of $6 \mathrm{mM}$. Optical recording was performed using an Olympus IXS1 inverted microscope equipped with a Hamamatsu ORCA-AG camera. Frames were acquired at 2-second intervals for a total of 4 minutes. Images were processed using ImageJ software. At each time point, Fluo-4 fluorescence was normalized to mCherry fluorescence. 


\section{Genetic mosaic analysis}

Mosaic analysis and statistical analysis were performed as previously described (Sagasti et al., 2001; VanHoven et al., 2006; Chuang et al., 2007). For experiments using the $s t r-1$ and $s r a-6$ promoters, bicistronic constructs were generated using the SL2 trans-splicing signal to drive both the gene of interest and mCherry, and mCherry expression determined retention of the transgenes. Previous studies showed that the $n s y-5$ promoter, odr-3 promoter, str-1 promoter, sra- 6 promoter, odr-1p::DsRed and various coinjection markers had no effect on str-2::GFP expression (Sagasti et al., 2001; Chuang and Bargmann, 2005; VanHoven et al., 2006; Bauer Huang et al., 2007; Chuang et al., 2007). At least two independent lines of the same transgene were analyzed. Expected numbers of mosaic animals were predicted from non-mosaic animals of the same transgenic line.

\section{RESULTS}

NSY-5 gap junctions mediate small molecule transfer between $C$. elegans embryonic neurons

Consistent with its cell-intrinsic and network functions in AWC asymmetry, NSY-5 can form both functional hemichannels and intercellular gap junction channels in Xenopus oocytes (Chuang et al., 2007). However, the permeability properties of NSY-5 gap junctions in C. elegans have not been examined. To determine the permeability of NSY-5 gap junctions to small molecules in $C$. elegans embryonic cells, we used a photoactivatable (caged) fluorescent dye and the uncaging/imaging technique (Dakin et al., 2005; Dakin and Li, 2006). Embryonic neurons were isolated from nsy-5p::mCherry transgenic animals, in which neurons of the NSY5 network were labeled with mCherry (Shaner et al., 2004; Shaner et al., 2005). Cultured neurons were loaded with the cell-permeable caged fluorophore NPE-HCCC2/AM (Zhao et al., 2004; Dakin et al., 2005). After entering the cell, the acetoxymethyl (AM) esters are hydrolyzed and the caged dye (NPE-HCCC2) becomes trapped inside the cell. When uncaged by UV light, the parent fluorophore HCCC2 is released. As the molecular weight of HCCC2 is $450 \mathrm{Da}$, well below the $\sim 1.2 \mathrm{kDa}$ molecular passage limit of typical gap junction channels (Kumar and Gilula, 1996), HCCC2 diffuses to its neighboring cells through gap junctions (Fig. 1A). We focused on pairs of nsy-5p::mCherry-expressing cells that made direct contact (Fig. 1B,C,I,J), and uncaged the fluorophore in one cell. In wild-type cell pairs, $\mathrm{HCCC} 2$ transferred rapidly from the uncaged cell (donor) to its neighboring cell (recipient) (Fig. 1E-H). By contrast, in cell pairs isolated from nsy-5 loss-of-function (lf) embryos, in which nsy-5-dependent gap junctions were absent (Chuang et al., 2007), fluorescent HCCC2 was only detected in the uncaged cell (cell 1) and no fluorescence was observed in its

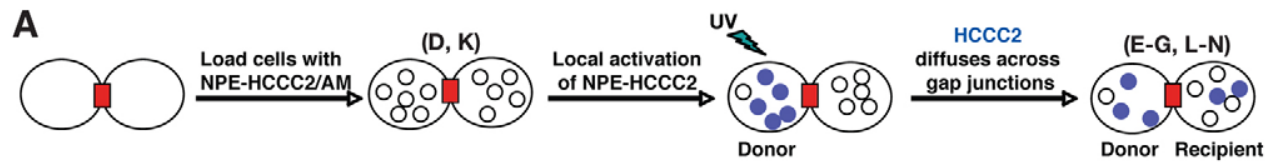

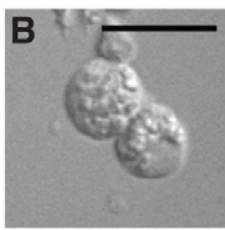
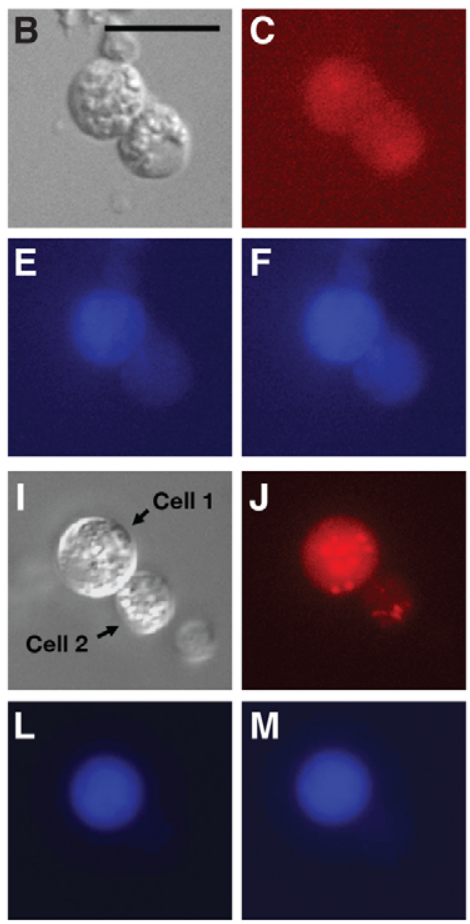
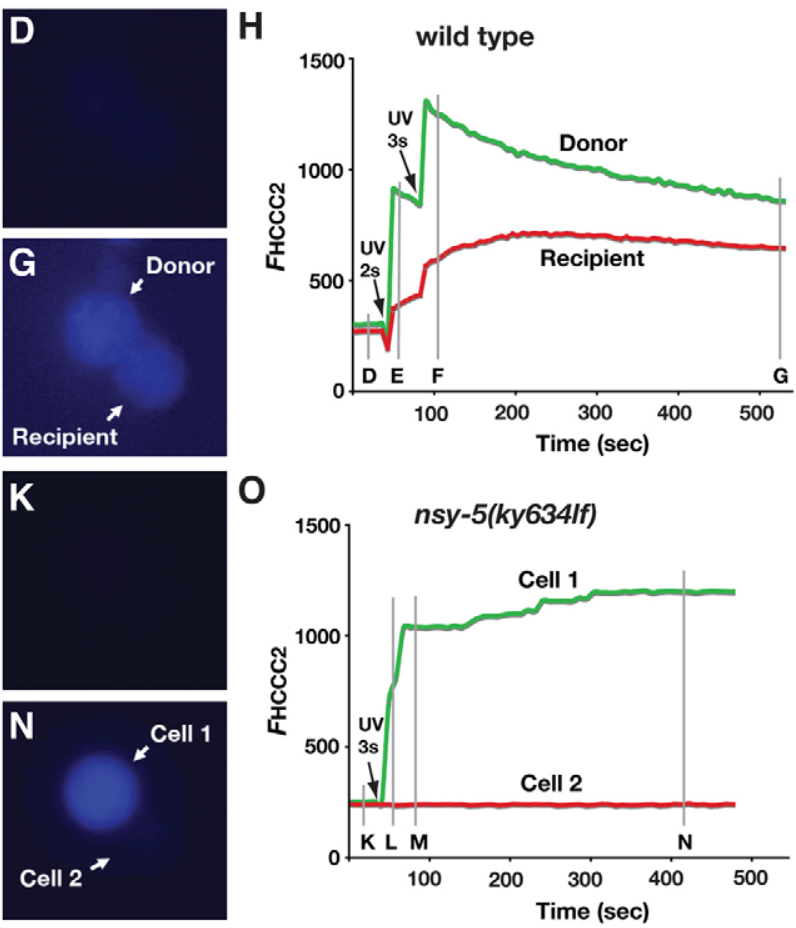

Fig. 1. NSY-5 gap junctions mediate small dye transfer between C. elegans embryonic neurons. (A) Schematic of the dye transfer technique. Black open circles, NPE-HCCC2; blue dots, HCCC2; red rectangles, gap junctions. (B-G) One pair of nsy-5p::mCherry cells from wild-type embryos. (B) Differential interference contrast (DIC) and (C) mCherry images. (D-G) Images of fluorescent HCCC2 in the coupled cells prior to UV $(360 \mathrm{~nm}$ ) uncaging (D), immediately after the first (E) and second (F) localized uncaging of one cell (donor), and when the transfer of fluorescent HCCC2 from donor cell to recipient cell reached equilibrium $(\mathrm{G})$. (H) Time course of fluorescence intensities of HCCC2 $\left(F_{\mathrm{HCCC} 2}\right)$ in the wild-type coupled cells. D, E, F and G indicate the time points at which the images in D, E, F and G, respectively, were acquired. (I-N) One pair of nsy$5 p:: m$ Cherry-expressing cells from nsy-5(ky634lf) embryos. (I) DIC and (J) mCherry images. (K-N) Images of fluorescent HCCC2 before localized uncaging of cell $1(\mathrm{~K})$, immediately after uncaging $(\mathrm{L})$ and 40 seconds $(\mathrm{M})$ and 380 seconds $(\mathrm{N})$ after uncaging. (O) Time course of fluorescence intensities of HCCC2 $\left(F_{\mathrm{HCCC}}\right)$ in the nsy-5(If) cell pair. K, L, M and N indicate the time points at which the images in K, L, M and N, respectively, were acquired. Scale bar: $10 \mu \mathrm{m}$. 
neighboring cell (cell 2) (Fig. 1L-O). These results indicate that NSY-5 gap junctions can mediate small molecule transfer between coupled C. elegans neurons.

\section{Expression of vertebrate calcium buffers proteins in a subset of NSY-5 network cells disrupts AWC asymmetry}

To determine the requirements for intracellular free calcium in specific cells within the NSY-5 network, we established transgenic lines expressing the vertebrate calcium-buffer proteins calbindin $\mathrm{D} 28 \mathrm{~K}$, parvalbumin or calbindin $\mathrm{D} 9 \mathrm{~K}$ in various subsets of neurons. Calcium-buffer proteins contain EF-hand domains (four functional domains in calbindin D28K and two each in parvalbumin and calbindin D9K) responsible for binding to and sequestering intracellular free calcium, preventing calcium from activating downstream targets such as CaMKII (Ikura, 1996). There are no homologs of these calcium buffer genes in the $C$. elegans genome (C. elegans Sequencing Consortium, 1998).

Expression of each buffer under the control of the odr-3 promoter (Roayaie et al., 1998), which is strongly expressed in AWC and weakly in AWB neurons, led to str-2::GFP expression in both $\mathrm{AWC}$ neurons (2AWC ${ }^{\mathrm{ON}}$ phenotype) (Fig. 2D,E; supplementary material Table S1), in contrast to the $1 \mathrm{AWC} \mathrm{CFF}^{\mathrm{OFF}} / 1 \mathrm{AWC} \mathrm{ON}^{\mathrm{ON}}$ phenotype observed in the wild-type population (Fig. 2A,E). The $2 \mathrm{AWC}^{\mathrm{ON}}$ phenotype is identical to the loss-of-function mutant phenotype of the calcium channel $\alpha 2 \delta$ subunit gene unc-36 (Troemel et al., 1999) (Fig. 2C,E; supplementary material Table S1), consistent with each buffer strongly inhibiting calcium signaling. Mutations of conserved charged residues at the beginning and end of the two EF-hand calcium-binding domains of parvalbumin reduce calcium binding in vitro (Pauls et al., 1994). To determine whether parvalbumin generates a $2 \mathrm{AWC}^{\mathrm{ON}}$ phenotype owing to its ability to bind calcium, we mutated all charged resides in the second EF-hand domain. This resulted in a significant reduction of $2 \mathrm{AWC}^{\mathrm{ON}}$ phenotype $(P=0.006, n=245)$, suggesting that the $2 \mathrm{AWC}^{\mathrm{ON}}$ phenotypes are specifically due to calcium-binding activity.

$n s y-5$ mutants have two $\mathrm{AWC}^{\mathrm{OFF}}$ cells (2AWC ${ }^{\mathrm{OFF}}$ phenotype) (Chuang et al., 2007) (Fig. 2B,E), consistent with the requirement of gap junction-mediated signaling for $\mathrm{AWC}^{\mathrm{ON}}$ induction. Calbindin D28K or parvalbumin expression in the entire NSY-5 network resulted in $2 \mathrm{AWC}^{\mathrm{ON}}$, but also significantly increased the percentage of $2 \mathrm{AWC}^{\mathrm{OFF}}$ compared with expression primarily in AWCs (Fig. 2E; supplementary material Table S1), suggesting that intracellular calcium signals in non-AWCs of the NSY-5 network promotes the wild-type $1 \mathrm{AWC} \mathrm{CN}^{\mathrm{ON}} / 1 \mathrm{AWC} \mathrm{OFF}^{\mathrm{OF}}$ phenotype.

odr-3p::calbindin D28K animals chemotaxed normally to butanone, which is sensed by the $\mathrm{AWC}^{\mathrm{ON}}$ cell, but did not chemotax to 2,3-pentanedione, which is sensed by the $\mathrm{AWC}^{\mathrm{OFF}}$ cell (Fig. 2F). These results confirm that the $\mathrm{AWC}^{\mathrm{OFF}}$ cell fate is lost in odr-3::calbindin $D 28 \mathrm{~K}$ animals, and that the $\mathrm{AWC}^{\mathrm{ON}}$ cells are capable of performing an appropriate physiological function. Because calbindin D28K has the highest number (four) of potential calcium-binding sites among the calcium-buffer proteins, we focused primarily on developing this buffer as a tool to examine the role of calcium in specific cells in the NSY-5 network.

\section{Calbindin D28K acts as a calcium buffer in NSY-5 network neurons}

Calcium-buffer proteins share the EF-hand calcium-binding domain with calcium sensors, which bind to calcium and promote signaling by activating downstream kinase cascades. Although it

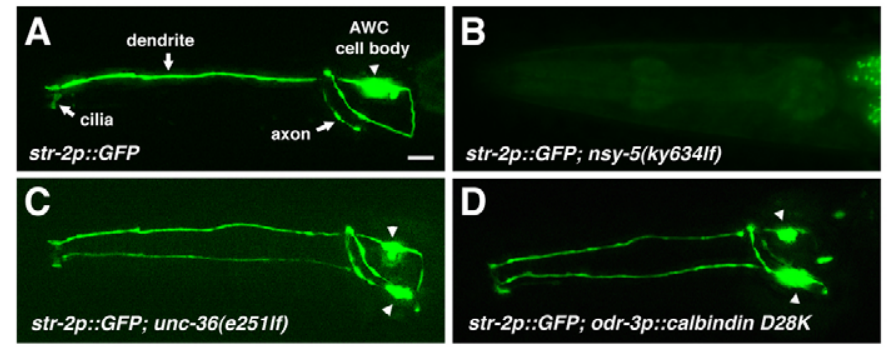

E

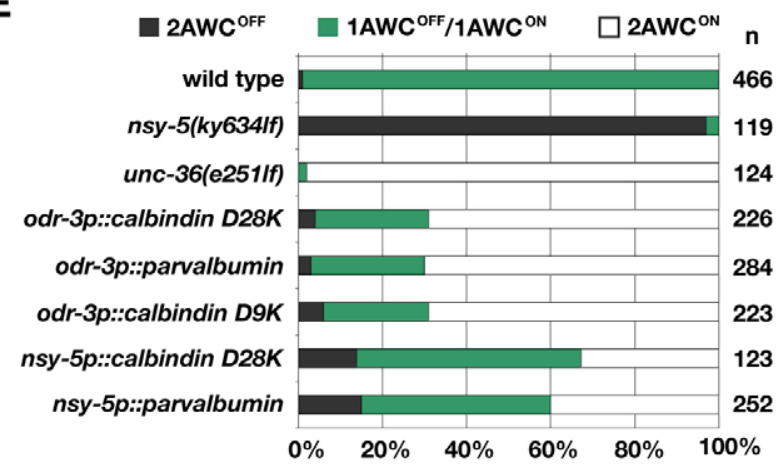

$\mathbf{F}$

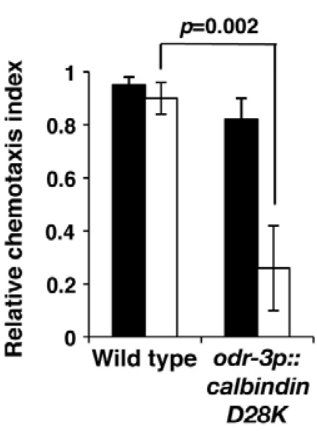

- bu (AWC ${ }^{\text {ON }}$-sensed odor) pd (AWC ${ }^{\text {OFF }}$-sensed odor)

Fig. 2. Calcium buffer expression in the NSY-5 network disrupts AWC asymmetric gene expression and function. (A-D) Expression of the reporter gene str-2p::GFP in wild type (A), nsy-5(ky634lf) (B), unc-36(e251/f) (C) and odr-3p::calbindin D28K transgenic worms (D). Anterior is left; ventral is down. Arrowheads indicate AWC cell bodies. Scale bar: $10 \mu \mathrm{m}$. (E) AWC phenotypes of wild type, mutants and calcium buffer-expressing animals. (F) Mean relative chemotaxis indices. Wild-type animals are non-transgenic siblings from odr-3p::calbindin D28K extrachromosomal arrays. bu, 1:1000 butanone; pd, 1:10,000 2,3-pentanedione. Significance was calculated using $t$-test. Error bars indicate s.e.m.

is well established that calbindin D28K and parvalbumin function as calcium buffers in vertebrate systems and transgenic fly neurons (Chard et al., 1993; Grabarek, 2006; Harrisingh et al., 2007), their calcium-buffering ability has not been tested in any type of C. elegans cells. unc-43/CaMKII gain-of-function (gf) mutants have a $2 \mathrm{AWC}^{\mathrm{OFF}}$ phenotype (Troemel et al., 1999) (Fig. 3A; supplementary material Table S1). To confirm that calbindin D28K does not promote calcium signaling, we compared the abilities of calbindin D28K and C. elegans CMD-1/calmodulin, a calcium sensor that activates CaMKII, to induce a $2 \mathrm{AWC}^{\mathrm{OFF}}$ phenotype. Neither protein when expressed alone in AWCs under the odr-3 promoter strongly induced a $2 \mathrm{AWC} \mathrm{CFF}^{\mathrm{OFF}}$ phenotype (Fig. 3A; supplementary material Table S1). Calcium concentration could be one of the limiting factors in allowing $\mathrm{cmd}-1$ to activate 


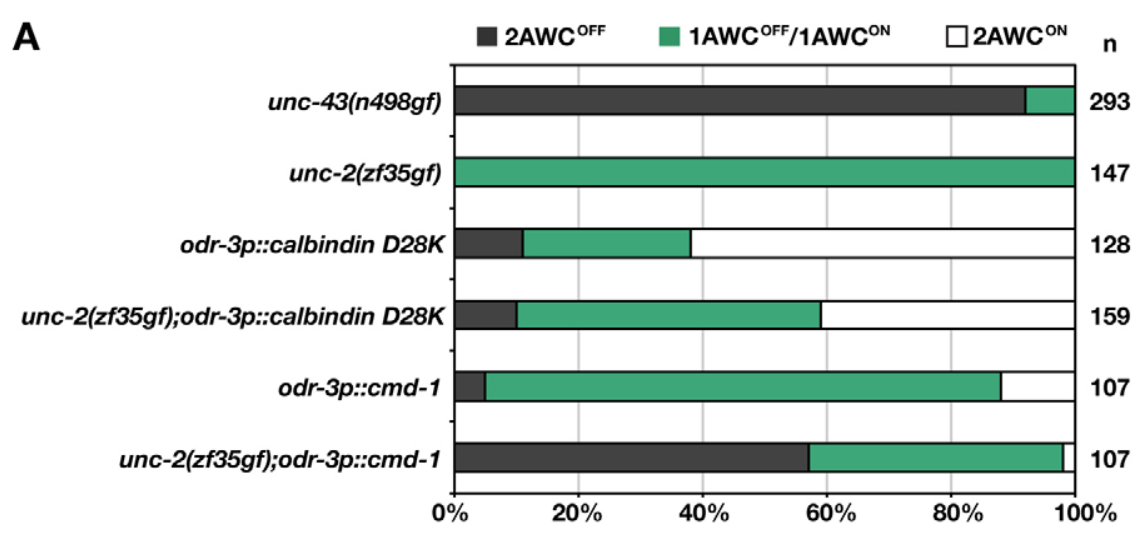

B

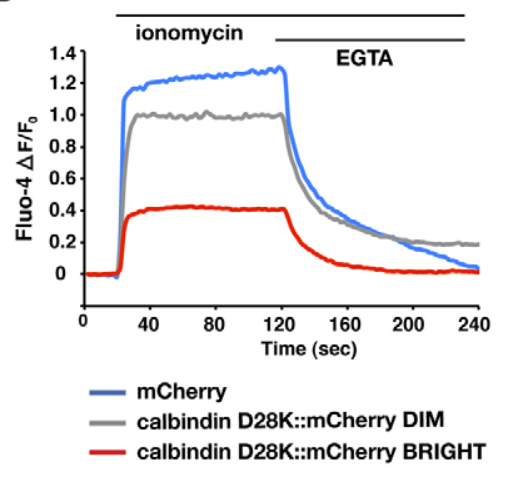

C

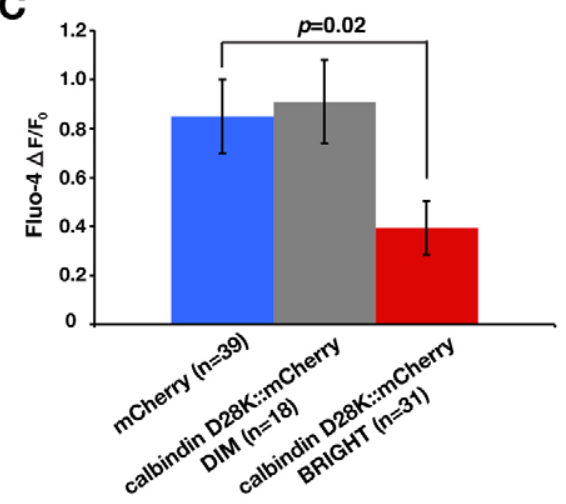

Fig. 3. Calbindin D28K acts as an intracellular calcium buffer in NSY-5 network embryonic neurons. (A) AWC phenotypes of calcium buffer (odr-3p::calbindin D28K) and calcium sensor (odr$3 p:: \mathrm{cmd}-1)$ expressing animals alone or in the unc-2(zf35gf) background. (B) Representative traces of calcium dynamics in cultured $C$. elegans embryonic neurons during addition of the stimulus (ionomycin) followed by calcium chelator (EGTA). Horizontal lines indicate the duration of ionomycin and EGTA application. $\Delta \mathrm{F}$, the change in Fluo-4 fluorescence; $F_{0}$, the resting Fluo-4 fluorescence prior to ionomycin stimulation. (C) Average maximum change in Fluo-4 intensity following ionomycin application. Significance was calculated using t-test. Error bars indicate s.e.m. downstream targets. unc-2(zf35) is a gain-of-function allele of the neuronal $\mathrm{P} / \mathrm{Q}$ type calcium channel (J.K.P. and M.J.A., unpublished), which should lead to a rise in intracellular calcium. Although unc-2(zf35gf) mutants had wild-type AWC asymmetry (Fig. 3A; supplementary material Table S1), they may provide a sensitized background for a $2 \mathrm{AWC}{ }^{\mathrm{OFF}}$ phenotype. When the same odr-3p::calbindin D28K or odr-3p::cmd-1 transgenes were expressed in unc-2(zf35gf) homozygous mutants, odr-3p::cmd-1 generated a strong $2 \mathrm{AWC}{ }^{\mathrm{OFF}}$ phenotype (Fig. 3A; supplementary material Table S1), indicative of promoting calcium signaling. Importantly, odr-3p::calbindin D28K did not promote $2 \mathrm{AWC} \mathrm{OFF}$ in the unc-2(zf35gf) background (Fig. 3A), indicating that calbindin D28K does not activate downstream targets and supporting the role of calbindin $\mathrm{D} 28 \mathrm{~K}$ as a calcium buffer rather than a calcium sensor.

To confirm that calbindin $\mathrm{D} 28 \mathrm{~K}$ reduces the amount of intracellular free calcium, we performed calcium-imaging experiments in C. elegans primary cell culture. We targeted neurons in the NSY-5 network by expressing mCherry or calbindin D28K::mCherry translational fusion protein under the control of the $n s y-5$ promoter. The $n s y-5 p::$ calbindin D28K::mCherry transgene allowed us to determine relative levels of calbindin D28K expression in each cell, which we broadly categorized into 'dim' cells, which had lower levels of calbindin D28K, and 'bright' cells, which had higher levels of calbindin D28K. Wild-type mCherry-expressing neurons displayed a typical increase in intracellular calcium measured by the calcium indicator Fluo-4 following ionomycin (a calcium ionophore) application (Fig. 3B,C). 'Dim' calbindin D28K::mCherry neurons had a similar increase to wild-type neurons (Fig. 3B,C). However, the increase in intracellular calcium was significantly reduced in 'bright' neurons, which expressed high levels of calbindin D28K::mCherry, indicating that calbindin D28K is able to bind and sequester intracellular calcium. Taken together, these results are consistent with calbindin D28K acting as a calcium buffer in the NSY-5 network to disrupt AWC asymmetry.

\section{Calcium buffers antagonize the unc-2/unc-36 calcium signaling pathway}

The $2 \mathrm{AWC}^{\mathrm{ON}}$ phenotype caused by calcium buffer expression in AWCs resembles that seen in loss-of-function mutations of unc-2 and unc-36 calcium channels and of the downstream calciumactivated unc-43 (CaMKII)/tir-1 (Sarm1 adaptor)/nsy-1 (MAPKKK) kinase pathway (Troemel et al., 1999; Sagasti et al., 2001; Chuang and Bargmann, 2005; Chang et al., 2011) (Fig. 4A,B). This similarity suggests that the calcium buffer-induced $2 \mathrm{AWC}^{\mathrm{ON}}$ phenotype could result from an inhibition of the unc2/unc-36 calcium signaling pathway.

To determine the relationship between the calcium-buffer target and other genes affecting AWC asymmetry, we crossed odr$3 p::$ calbindin D28K or odr-3p::parvalbumin transgenic animals $\left(2 \mathrm{AWC} \mathrm{ON}^{\mathrm{N}}\right.$ ) with $2 \mathrm{AWC} \mathrm{OFF}^{\mathrm{OF}}$ mutants. Loss-of-function mutations in the $u n c-76$ axon outgrowth gene, the $n s y-5$ innexin gene and the $n s y$-4 claudin-like gene, or gain-of-function mutations in the unc43 CaMKII gene cause a $2 \mathrm{AWC}^{\mathrm{OFF}}$ phenotype (Troemel et al., 1999; VanHoven et al., 2006; Chuang et al., 2007) (Fig. 4A,B). Calbindin D28K or parvalbumin expression strongly suppressed the $2 \mathrm{AWC}{ }^{\mathrm{OFF}}$ phenotype of $u n c-76(l f), n s y-5(l f)$ or $n s y-4(l f)$ mutants (Fig. 4A), indicating that calcium buffers function downstream of axon outgrowth, $n s y-5$ and $n s y-4$ (Fig. 4B). By contrast, the $2 \mathrm{AWC}^{\mathrm{ON}}$ phenotype resulting from calbindin $\mathrm{D} 28 \mathrm{~K}$ or parvalbumin expression was greatly suppressed by unc-43 gainof-function mutants (Fig. 4A), suggesting that calcium buffers act on a target predominantly upstream of $u n c-43$ (Fig. 4B). 


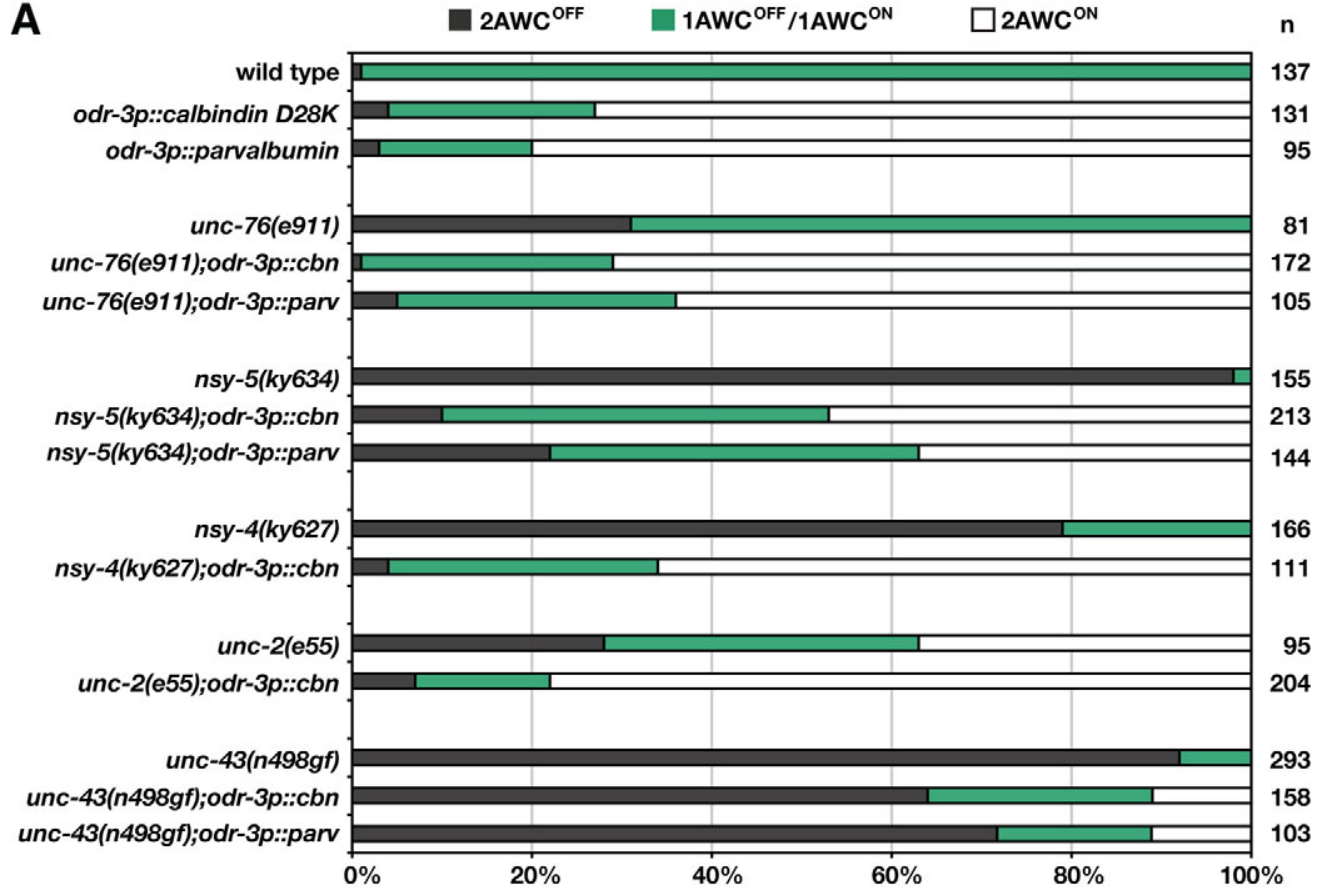

B

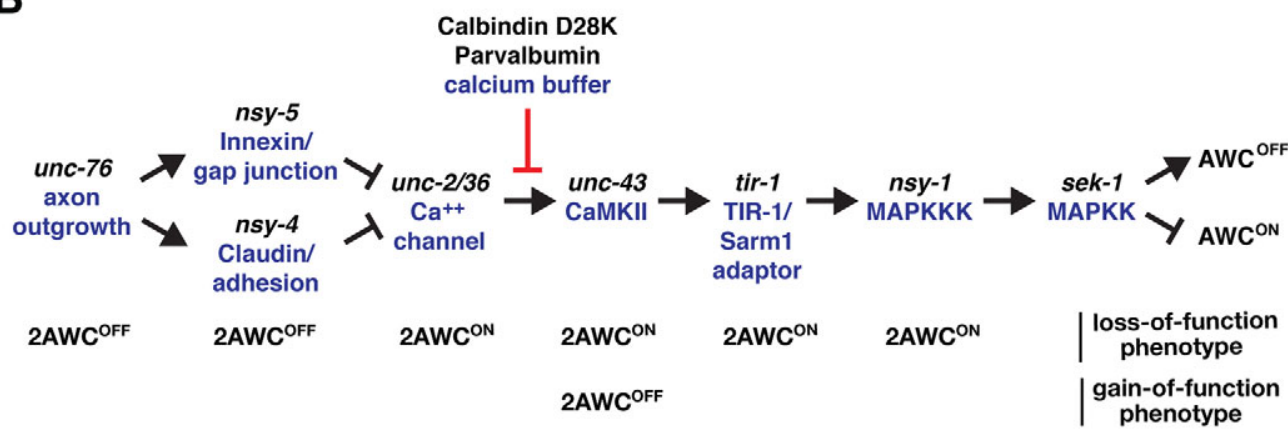

Fig. 4. Calcium buffers antagonize the unc-2/unc-36 calcium signaling pathway. (A) AWC phenotypes of animals expressing calcium buffers alone or in mutants defective in AWC asymmetry. cbn, calbindin D28K; parv, parvalbumin. (B) The AWC asymmetry determination pathway.
These results suggest that calcium buffers affect the AWC signaling step downstream of $n s y-5$ and $n s y-4$, and upstream of $u n c-43$. Previous genetic studies suggest that $u n c-2$ and $u n c-36$ calcium channels also act downstream of $n s y-5$ and $n s y-4$, and upstream of unc-43 (Troemel et al., 1999; VanHoven et al., 2006; Chuang et al., 2007). Thus, we examined the genetic interaction between the calcium-buffer target and unc-2. The unc-2(e55) mutant had a mixed $2 \mathrm{AWC}^{\mathrm{ON}}$ and $2 \mathrm{AWC}^{\mathrm{OFF}}$ phenotype due to functional redundancy of $u n c-2$ with the additional $\alpha 1$ subunit egl19 and inhibition of egl-19 activity by unc-2, respectively (Troemel et al., 1999; Bauer Huang et al., 2007) (Fig. 4A). Calbindin D28K expression significantly suppressed the $2 \mathrm{AWC}{ }^{\mathrm{OFF}}$ phenotype of unc-2(e55) mutants (Fig. 4A). Together, these results are consistent with the antagonistic effect of calcium buffers on the unc-2/unc-36 calcium signaling pathway (Fig. 4B).

\section{Intracellular calcium acts cell-autonomously in AWCs to promote AWC ${ }^{\text {OFF }}$}

Based on previous results that calcium-signaling components (unc43 , tir-1, nsy-1) function cell-autonomously to execute the AWC ${ }^{\mathrm{OFF}}$ fate (Sagasti et al., 2001; Chuang and Bargmann, 2005), we hypothesized that the calcium buffers would cell-autonomously inhibit the calcium-signaling pathway to promote $\mathrm{AWC}^{\mathrm{ON}}$. To test this hypothesis, we performed genetic mosaic analysis using calbindin D28K transgenes expressed primarily in AWCs and AWBs using the odr-3 promoter. Transgenes are inherited as extrachromosomal arrays that are unstable and subject to spontaneous mitotic loss in random cell lineages. Mosaic animals were identified by loss of the co-injection marker odr-1p $:$ DsRed, which is expressed in AWC left (AWCL), AWC right (AWCR), AWB left (AWBL) and AWB right (AWBR). These four cells represent four lineage groups within the NSY-5 network (Chuang et al., 2007) (supplementary material Fig. S1), and thus can serve as indicators of which cells within the network retain or lose calbindin D28K transgenes. Seventy percent of non-mosaic calbindin D28K animals had 2AWC ${ }^{\mathrm{ON}}$ (Fig. 5B; Table 1, row d). Non-mosaic $1 \mathrm{AWC}^{\mathrm{ON}}$ animals showed no side bias of $\mathrm{AWC}^{\mathrm{ON}}$ induction. In $>90 \%$ of mosaic animals that retained the calcium buffer only in one AWC, the calcium-buffered AWC became $\mathrm{AWC}^{\mathrm{ON}}$ and the wild-type $\mathrm{AWC}$ became $\mathrm{AWC} \mathrm{OFF}^{\mathrm{OF}}$, independent of expression of the buffer in AWB cells (Fig. 5C; Table 1, rows e,f). This suggests that intracellular calcium is required cellautonomously to execute $\mathrm{AWC}{ }^{\mathrm{OFF}}$ cell-fate specification (Fig. 6A).

\section{Intracellular calcium signals in non-AWCs promotes $1 \mathrm{AWC}^{\mathrm{ON}} / 1 \mathrm{AWC}^{\mathrm{OFF}}$}

Based on our observation that expressing the buffers in the entire NSY-5 network led to a moderate $2 \mathrm{AWC}{ }^{\mathrm{OFF}}$ phenotype (Fig. 2E), 

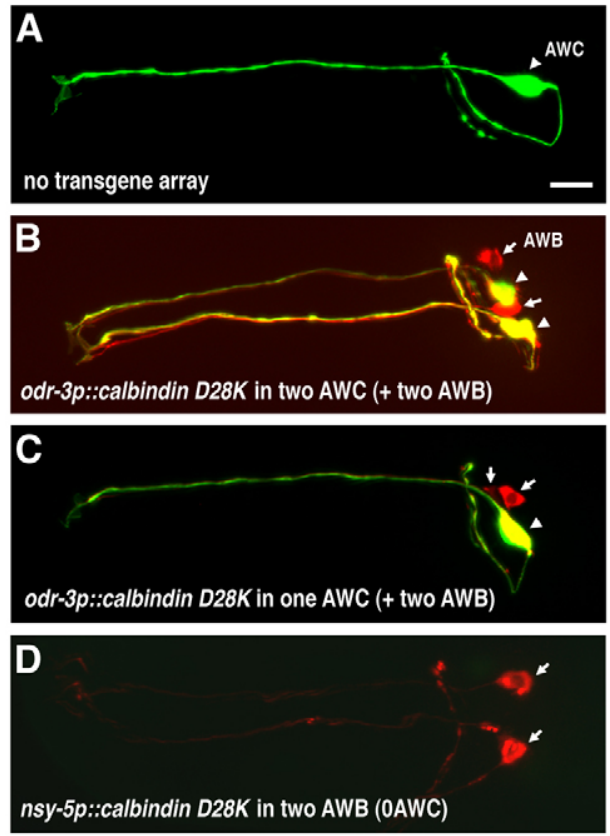

Fig. 5. Calcium acts autonomously in AWCs to promote AWC ${ }^{\text {OFF }}$ and non-autonomously in non-AWCs to promote $A W C^{\mathrm{ON}}$. (A-D) Expression of an integrated str-2p::GFP transgene and an unstable transgenic array bearing odr-3p::calbindin D28K or nsy$5 p::$ calbindin D28K and the mosaic marker odr-1p::DsRed in nontransgenic $(A)$, non-mosaic $(B)$ and representative mosaic $(C, D)$ worms. AWC neurons that express both GFP and DsRed appear yellow. (C) Mosaic animal that retains odr-3p:::calbindin D28K in AWCL. (D) Mosaic animal that lost $n s y-5 p::$ calbindin D28K in both AWCs but retained the transgene in both AWBs. Arrowheads indicate AWC cell bodies; arrows indicate AWB cell bodies. Anterior is left; ventral is down. Scale bar: $10 \mu \mathrm{m}$.

we hypothesized that calcium within non-AWC cells is required to promote $1 \mathrm{AWC}^{\mathrm{ON}} / 1 \mathrm{AWC} \mathrm{OFF}^{\mathrm{O}}$. To test this hypothesis, we performed mosaic analysis with the $n s y-5 p::$ calbindin $D 28 K$; odr-1p::DsRed transgenic extrachromosomal arrays to determine whether buffering calcium only in non-AWC neurons within the NSY-5 network was able to disrupt asymmetry. As 15 out of the 34 non-AWC cells expressing $n s y-5$ are closely related to either AWB by lineage (Chuang et al., 2007) (supplementary material Fig. S1), their genotypes can be inferred by following the odr$1 p::$ DsRed expression in AWB. If calcium signaling in non-AWC cells is required for $\mathrm{AWC}^{\mathrm{ON}}$ induction, buffering of calcium signals in the AWB lineage would disrupt intercellular calcium signaling within the NSY-5 network and lead to a defect in the induction of $\mathrm{AWC}^{\mathrm{ON}}$ fate. Thus, we examined mosaic animals that had odr-1p::DsRed expression in both AWB cells but not in either AWC, which would have buffered calcium levels in $\sim 50 \%$ of non-AWCs in the NSY-5 network. Interestingly, 79\% of this type of mosaic animals had $2 \mathrm{AWC}{ }^{\mathrm{OFF}}$ (Fig. 5D; Table 1, row c). In addition, we examined odr-3p::calbindin $D 28 K$ mosaic animals that retained the array only in both AWC cells, and found that only $38 \%$ of animals had $2 \mathrm{AWC}^{\mathrm{ON}}$ (Table 1 , row $\mathrm{g}$ ), compared with $70 \%$ when calcium was buffered in both AWCs and AWBs (Table 1, row d). These results support the hypothesis that intracellular calcium in non-AWC cells of the NSY-5 network is required to promote $1 \mathrm{AWC}^{\mathrm{ON}} / 1 \mathrm{AWC} \mathrm{CFF}^{\mathrm{OF}}$ (Fig. 6B; supplementary material Fig. S2A).

\section{Calcium in AWB and ASH contributes to AWC ${ }^{\text {ON }}$ side bias}

To refine the requirements of calcium in the AWB lineage further, we examined the role of calcium in AWBs. We examined mosaic animals that lost the odr-3p::calbindin D28K array only in AWBL or AWBR, and determined whether AWCL or AWCR becomes $\mathrm{AWC}^{\mathrm{ON}}$. Of the $1 \mathrm{AWC}^{\mathrm{ON}}$ mosaic animals that lost the odr$3 p::$ calbindin D28K array in AWBR, $74-77 \%$ had a significant bias towards the opposite side AWCL becoming $\mathrm{AWC}^{\mathrm{ON}}$, regardless of the presence of the transgene in both AWCs (Table 1, rows h,j). Because AWB inhibits AWC ${ }^{\mathrm{ON}}$ fate via NSY-5 (Chuang et al., 2007), these results are consistent with the hypothesis that normal calcium levels in AWBR inhibits AWCR from becoming $\mathrm{AWC}^{\mathrm{ON}}$. In the nsy-5(lf) mutant, mosaic animals that lost the array in AWBR no longer had a bias towards $\mathrm{AWCL}^{\mathrm{ON}}$ (Table 1 , rows $\mathrm{j}, \mathrm{m}$ ), suggesting that calcium in AWBR requires gap-junction communication within the NSY-5 network to inhibit AWCR ${ }^{\mathrm{ON}}$. In addition, this result supports the notion that calcium travels through NSY-5 gap junctions within the network.

To probe the role for AWB further, we used the str-1 promoter (Troemel et al., 1997) to drive expression of calbindin D28K only in AWB. Expression of str-1p::calbindin D28K in both AWBL and AWBR did not disrupt AWC asymmetry (Table 1, row n; supplementary material Table S1), whereas the similar class of animals containing the $n s y-5 p::$ calbindin $D 28 K$ array did disrupt AWC asymmetry (Table 1, row c). These results suggest that other cells in the AWB lineage of the NSY-5 network also contribute to promoting the wild-type $1 \mathrm{AWC} \mathrm{CN}^{\mathrm{ON}} / 1 \mathrm{AWC} \mathrm{OFF}^{\mathrm{OF}}$ fate. Mosaic animals that lost str-1p::calbindin D28K in AWBR had a significant bias towards AWCL ${ }^{\mathrm{ON}}$ (Table 1, row o), confirming that the negative influence on $\mathrm{AWCR}^{\mathrm{ON}}$ via calcium is partly, if not completely, derived from AWBR (supplementary material Fig. S2B). Control mosaic experiments showed that str-1p::mCherry did not influence $\mathrm{AWC}^{\mathrm{ON}}$ side bias (supplementary material Table S2). To test whether $n s y-5$, like calcium, in AWBR generates $\mathrm{AWCL}^{\mathrm{ON}}$ side bias, we made a tissue-specific inverted repeat (IR) RNAi construct, str-1p::nsy-5IR. Knocking down NSY-5 in both AWBL and AWBR did not disrupt AWC asymmetry or generate an $\mathrm{AWC}^{\mathrm{ON}}$ side bias (Table 1, row q). Consistent with our str$1 p::$ calbindin $D 28 K$ results (Table 1, row o), $62 \%$ of $1 \mathrm{AWC}^{\mathrm{ON}}$ animals that lost str-1p::nsy-5IR in AWBR had a significant bias towards $\mathrm{AWCL}^{\mathrm{ON}}$ (Table 1, row r). These results suggest that the negative influence of AWBR on $\mathrm{AWCR}^{\mathrm{ON}}$ is dependent on both calcium and $n s y-5$. In addition, $70 \%$ of $1 \mathrm{AWC}^{\mathrm{ON}}$ animals that lost str-1p::nsy-5IR in AWBL had a significant bias towards $\mathrm{AWCR}^{\mathrm{ON}}$ (Table 1, row s). As the same class of mosaic animals containing the str-1p::calbindin D28K did not show a bias towards $\mathrm{AWCR}^{\mathrm{ON}}$ (Table 1, row $\mathrm{p}$ ), these results suggest that other signals from AWBL might go through NSY-5 gap junctions to negatively influence $\mathrm{AWCL}{ }^{\mathrm{ON}}$

ASH neurons are derived from the same lineage as AWCs. To examine whether calcium in $\mathrm{ASH}$ generates $\mathrm{AWC}^{\mathrm{ON}}$ side bias, we used the sra-6 promoter (Troemel et al., 1995) to drive calbindin D28K expression primarily in ASH, in addition to ASI neurons. Expression of sra-6p::calbindin D28K in both ASH and ASI did not disrupt AWC asymmetry nor did it generate $\mathrm{AWC}^{\mathrm{ON}}$ side bias (Table 1, row t; supplementary material Table S1). Mosaic animals that lost the array in ASHL had a significant bias towards $\mathrm{AWCL}^{\mathrm{ON}}$ (Table 1, row v). Control mosaic experiments showed that sra-6p::SL2::mCherry did not influence $\mathrm{AWC}^{\mathrm{ON}}$ side bias (supplementary material Table S2). ASH was previously shown to promote $\mathrm{AWC}^{\mathrm{ON}}$ fate via NSY-5 (Chuang et al., 2007), suggesting 
Table 1. Individual neurons in the NSY-5 network play specific roles in influencing AWC ${ }^{\mathrm{N}}$ fate and side bias

\begin{tabular}{|c|c|c|c|c|c|c|c|c|c|c|c|}
\hline \multirow{2}{*}{$\begin{array}{l}\text { Genetic } \\
\text { background }\end{array}$} & \multirow{2}{*}{$\begin{array}{c}\text { Transgene } \\
\text { array }\end{array}$} & \multirow[b]{2}{*}{ Row } & \multicolumn{4}{|c|}{ Cells with transgene array } & \multicolumn{4}{|c|}{ str-2p::GFP phenotype (\%) } & \multirow[b]{2}{*}{$n$} \\
\hline & & & AWCL & AWCR & AWBL & AWBR & 2AWCOFF & AWCLON & $A W C R^{O N}$ & 2AWCON & \\
\hline \multirow[t]{11}{*}{ Wild type } & $\begin{array}{c}n s y-5 p:: \\
\text { calbindin } \\
D 28 K\end{array}$ & a & - & - & - & - & 0 & 46 & 54 & 0 & 254 \\
\hline & & $b$ & + & + & + & + & 10 & $20(49)$ & $21(51)$ & 49 & $\begin{array}{l}1266 \\
(519)\end{array}$ \\
\hline & & c & - & - & + & + & $79 * * * * b$ & 4 & 17 & 0 & 29 \\
\hline & $\begin{array}{c}\text { odr-3p:: } \\
\text { calbindin } \\
\text { D28K }\end{array}$ & d & + & + & + & + & 2 & $13(46)$ & $15(54)$ & 70 & $\begin{array}{l}1492 \\
(418)\end{array}$ \\
\hline & & e & - & + & $+/-$ & $+/$ & 7 & 2 & $\begin{array}{c}91 \\
(\mathbf{9 8})^{* * * * d}\end{array}$ & 0 & $\begin{array}{c}109 \\
(101)\end{array}$ \\
\hline & & $f$ & + & - & $+1-$ & $+/-$ & 6 & $\begin{array}{c}90 \\
(96)^{\star * \star * d}\end{array}$ & 4 & 0 & $99(93)$ \\
\hline & & g & + & + & - & - & 0 & 33 & 29 & $38 * * * d$ & 24 \\
\hline & & $\mathrm{h}$ & - & - & + & - & 0 & $77 * * d$ & 23 & 0 & 22 \\
\hline & & $\mathrm{i}$ & - & - & - & + & 0 & 80 & 20 & 0 & 5 \\
\hline & & j & + & + & + & - & 1 & 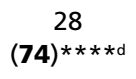 & $10(26)$ & 61 & $171(65)$ \\
\hline & & k & + & + & - & + & 3 & 14 & 16 & 67 & 154 \\
\hline \multirow[t]{2}{*}{$n s y-5(k y 634)$} & $\begin{array}{c}\text { odr-3p:: } \\
\text { calbindin } \\
\text { D28K }\end{array}$ & 1 & + & + & + & + & 12 & $18(47)$ & $20(53)$ & 50 & $\begin{array}{l}1224 \\
(465)\end{array}$ \\
\hline & & $\mathrm{m}$ & + & + & + & - & 9 & $26(51)^{\mathrm{ns} I}$ & $25(49)$ & 39 & $\begin{array}{c}214 \\
(110)\end{array}$ \\
\hline \multirow[t]{6}{*}{ Wild type } & $\begin{array}{c}\text { str-1p:: } \\
\text { calbindin } \\
\text { D28K }\end{array}$ & $\mathrm{n}$ & & & + & + & 3 & $38(39)$ & $59(61)$ & 0 & $\begin{array}{c}1258 \\
(1220)\end{array}$ \\
\hline & & o & & & + & - & 0 & $58^{* * n}$ & 42 & 0 & 62 \\
\hline & & $p$ & & & - & + & 0 & 35 & $65^{\text {ns } n}$ & 0 & 57 \\
\hline & $\begin{array}{l}\text { str-1p:: } \\
n s y-5 / R\end{array}$ & $q$ & & & + & + & 4 & $44(46)$ & $52(54)$ & 0 & $\begin{array}{c}445 \\
(427)\end{array}$ \\
\hline & & $r$ & & & + & - & 4 & $\begin{array}{c}59 \\
(\mathbf{6 2}) \star \star a\end{array}$ & $37(38)$ & 0 & $76(73)$ \\
\hline & & s & & & - & + & 6 & $28(30)$ & $66(\mathbf{7 0}) \star q$ & 0 & $61(57)$ \\
\hline \multirow{6}{*}{ Wild type } & sra-6p:. & & ASHL & ASHR & ASIL & ASIR & & & & & \\
\hline & $\begin{array}{l}\text { calbindin } \\
\text { D28K }\end{array}$ & $\mathrm{t}$ & + & + & + & + & 1 & 43 & 56 & 0 & 425 \\
\hline & & $\mathrm{u}$ & + & - & $+1-$ & $+1-$ & 0 & 53 & 47 & 0 & 45 \\
\hline & & $v$ & - & + & $+1-$ & $+1-$ & 2 & $59(60) * * t$ & $39(40)$ & 0 & $69(68)$ \\
\hline & & w & + & + & + & - & 0 & 25 & $75^{\star * t}$ & 0 & 55 \\
\hline & & $x$ & + & + & - & + & 4 & 49 & 47 & 0 & 51 \\
\hline
\end{tabular}

The odr-3p::calbindin D28K; odr-1p::DsRed transgene analyzed in rows d-k was crossed into the $n s y$-5(ky634lf) mutant for the analysis in rows l, m.

The str-1p::nsy-5IR::SL2::mCherry transgene was analyzed in the RNAi-sensitive strain eri-1(mg366); lin-15B(n744) (Sieburth et al., 2005).

+ , cells that retain the array; - , cells that lost the array; $n$, number of animals characterized.

cbn, calbindin D28K.

Data in parentheses are the percentages or numbers of animals with $A W C L^{\mathrm{ON}}$ and $A W C R^{\mathrm{ON}}$, calculated when the data of $2 A W C^{\mathrm{OFF}}$ and $2 A W C^{\mathrm{ON}}$ phenotypes are excluded.

Values in bold are significantly different from the expected values in the same column (row indicated by b,d,l,n,q,t). Significance was calculated using Z-test for two proportions.

$* * * * P<0.0001 ; * * * P=0.001 ; * * P<0.01$ (rows $\mathrm{h}, \mathrm{o}, \mathrm{v}, \mathrm{w}$ ) or $* * P=0.01$ (row $\mathrm{r}$ ); ${ }^{*} P=0.02 ;$ ns, not significant.

that calcium in ASHL promotes $\mathrm{AWCL}^{\mathrm{ON}}$ fate (supplementary material Fig. S2C). In addition, mosaic animals that lost the sra6p::calbindin array in ASIR had a significant bias towards AWCR ${ }^{\mathrm{ON}}$ (Table 1, row w). It has not been determined whether ASI has a positive or negative influence on $\mathrm{AWC}^{\mathrm{ON}}$ fate. ASIR is derived from the same lineage as AWBR and AFDR (supplementary material Fig. S1), which both inhibit AWC ${ }^{\mathrm{ON}}$ (Chuang et al., 2007), so it is possible that calcium in ASIR inhibits $\mathrm{AWCL}^{\mathrm{ON}}$ fate.

\section{IP3 and serotonin signaling are not required for AWC asymmetry}

Intercellular calcium waves can be propagated by movement of inositol trisphosphate (IP3) through gap junctions (Sáez et al., 1989). In addition, serotonin may move through gap junctions to coordinate the left-right body axis and modulate intercellular calcium signaling, and ADF neurons of the NSY-5 network synthesize serotonin (Blomstrand et al., 1999; Duerr et al., 1999; 


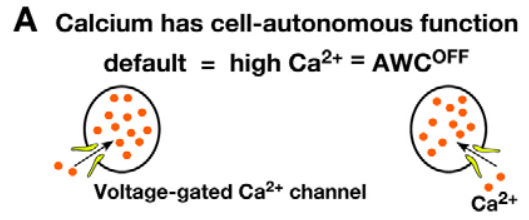

B Calcium has nsy-5-dependent non-cell-autonomous function

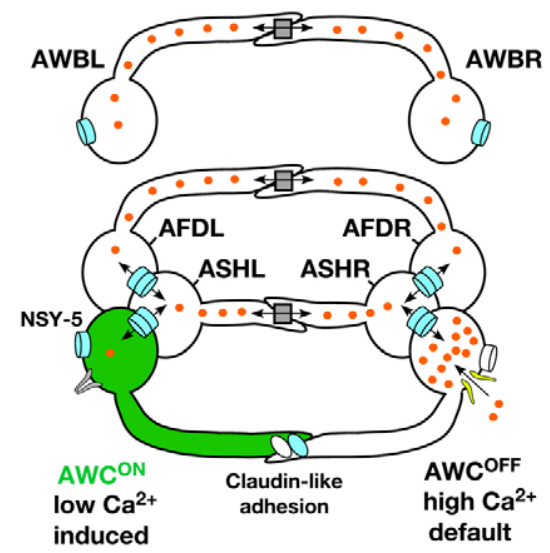

Fig. 6. Model of calcium function in left-right AWC asymmetry. (A) Calcium functions cell-autonomously within AWCs to promote the AWC ${ }^{\mathrm{OFF}}$ fate. Both AWC cells, before cell-cell communication, have calcium influx through voltage-gated calcium channels to maintain the default AWC ${ }^{\text {OFF }}$ fate. (B) Calcium mediates intercellular signaling between non-AWCs and AWCs within the NSY-5 network to induce one $\mathrm{AWC}^{\mathrm{ON}}$ and thus has a nsy-5-dependent non-cell-autonomous role in AWC asymmetry. The relative calcium level in the two AWC cells determines asymmetric AWC subtypes: the AWC with a lower calcium level becomes the induced $A W C^{O N}$, whereas the contralateral AWC with a higher level of calcium remains as the default AWC ${ }^{\text {OFF. }}$. AWB cells express nsy-5, but do not directly contact AWC. AWBs may communicate with AWCs through other cells in the NSY-5 network. Gray rectangles represent gap junctions identified from EM reconstructions of adult (White et al., 1986). Blue cylinders represent NSY-5 gap junction channels.

Zimmermann and Walz, 1999; Sze et al., 2000; Fukumoto et al., 2005a; Fukumoto et al., 2005b; Peters et al., 2005; Levin et al., 2006). To address potential roles of IP3 and serotonin in mediating $\mathrm{AWC}$ asymmetry, we examined $\mathrm{AWC}^{\mathrm{ON}}$ induction in mutants that disrupt components of each signaling pathway. We analyzed mutants of the following genes required for IP3 signaling: itr-1 (a single IP3 receptor), lfe-2 (IP3 kinase), ipp-5 (5-phosphatase) and plc-3 (phospholipase C) (Clandinin et al., 1998; Dal Santo et al., 1999; Sze et al., 2000; Bui and Sternberg, 2002). IP3 signaling mutants did not affect AWC asymmetry (supplementary material Table S3). C. elegans has a single tryptophan hydroxylase (the key enzyme for serotonin biosynthesis) gene, $t p h-1$, and tph-1(mg280lf) mutants do not synthesize serotonin (Sze et al., 2000). tph-1(mg280lf) mutants had wild-type AWC asymmetry (supplementary material Table S3). Together, these results suggest that IP3 and serotonin are not involved in $n s y$-5-mediated intercellular signaling for AWC asymmetry.

\section{DISCUSSION}

Discovering the nature of intercellular signaling is an important step towards understanding how groups of cells coupled by gap junctions coordinately communicate to diversify cell fates. We have taken advantage of well-characterized vertebrate calcium-buffer proteins and powerful $C$. elegans genetic tools to manipulate intracellular calcium levels selectively in individual cells or small groups of cells within the NSY-5 gap junction network to determine the non-cell-autonomous role of calcium in AWC fate diversification across the left-right axis. The genetic mosaic results revealed that calcium in non-AWC neurons of the NSY-5 network promotes wild-type $1 \mathrm{AWC} / \mathrm{ON} / 1 \mathrm{AWC}^{\mathrm{OFF}}$ cell fate decision. In addition, calcium in AWB, ASH and ASI cells influences $\mathrm{AWC}^{\mathrm{ON}}$ side biases. To our knowledge, this is the first in vivo study that directly reveals novel roles for intercellular calcium signaling within a gap junction network and dissects roles for specific cells in the network in stochastic cell-fate choice. In addition, the calcium-buffer transgenic lines represent a unique system in which to rigorously test the actual role of intracellular calcium in various neurons in directing cell-fate choice, rather than simply correlating calcium dynamics with cell-fate outcomes.

Based on the mosaic results, we propose a model in which calcium regulates AWC asymmetry by providing both cellautonomous inputs from AWCs and non-cell-autonomous inputs from other neurons in the NSY-5 network (Fig. 6). Prior to their interaction, the two AWC neurons have spontaneous activity in order to maintain voltage-gated calcium channel-mediated signaling and the default AWC $^{\text {OFF }}$ fate (Troemel et al., 1999; Sagasti et al., 2001; Tanaka-Hino et al., 2002; Chuang and Bargmann, 2005; VanHoven et al., 2006; Bauer Huang et al., 2007; Chuang et al., 2007) (Fig. 6A). Once the AWC cells sense each other's presence through intercellular calcium signaling between AWCs and other neurons within the NSY-5 network, calcium channels in the two AWC cells may be differentially regulated by an initial stochastic signaling event that breaks AWC symmetry. Voltage-gated calcium channels generate both calcium and voltage signals, and are subject to both calcium- and voltage-dependent activation and inactivation (Catterall, 2000). As calcium-activated signaling pathways are very sensitive to the temporal pattern of calcium signals (Thomas et al., 1996; West et al., 2001), transient differences in calcium influx between two cells can potentially generate sustained differences in calcium-regulated signaling outputs through positive- and negative-feedback mechanisms. Our results support the model that NSY-5 gap junctions transmit or modify calcium signals across the neural network, leading to differential regulation of calcium channel activity in the two AWC cells and the subsequent asymmetric differentiation of AWC cells (Fig. 6B). This extends the previous model of NSY-5 function by identifying calcium as a major mediator of intercellular communication in the NSY-5 network.

Gap junction-dependent intercellular calcium signaling has been observed in a number of different cell types and organ systems, including the neocortex, retina, airway epithelia, hepatocytes and osteoblastic cells (Sáez et al., 1989; Boitano et al., 1992; Yuste et al., 1992; Lee et al., 1994; Yuste et al., 1995; Kandler and Katz, 1998; Singer et al., 2001). One mechanism for transduction of these calcium waves is the spread of the second messenger IP3 through gap junctions, which then triggers the release of intracellular calcium stores in neighboring cells. Our results suggest that AWC asymmetry does not rely on IP3 signaling, implying an alternative mechanism for propagation of calcium signaling in the NSY-5 network. One possibility is that calcium itself travels through gap junctions to mediate intercellular communication. This type of communication is found in coupled hepatocytes, in which calcium diffusion through gap junctions may help to equalize hormonal 
responses across a field of cells (Sáez et al., 1989). In addition, membrane potential is a possible signal that mediates NSY-5 gap junction intercellular communication. In support of this notion, SLO-1 and EGL-2, which represent two different classes of voltage-regulated potassium channels, also affect AWC asymmetry (Troemel et al., 1999; Sagasti et al., 2001; Davies et al., 2003).

It is clear from these results that AWC neurons integrate signals from a number of different cells both to induce $\mathrm{AWC}^{\mathrm{ON}}$ and to influence $\mathrm{AWC}^{\mathrm{ON}}$ side bias. In particular, the mosaic analysis in $n s y-5$ (lf) mutants revealed that the calcium input from AWBR requires the presence of NSY-5 gap junctions to inhibit $\mathrm{AWCR}^{\mathrm{ON}}$, suggesting that there is a flow of information from AWBR to AWCR through gap junctions. AWBs do not form direct gap junctions with AWCs (Chuang et al., 2007), thus the influence from AWBs on AWCs might go through other cells in the NSY-5 network. However, it is possible that AWCR or AWCL receive inputs from additional neurons that were not included in this analysis. AWCR can respond to $n s y-5$ directly but AWCL requires $n s y-5$ function in multiple cells of the network (Chuang et al., 2007), suggesting that AWCL requires more inputs from neighboring cells to become $\mathrm{AWC} \mathrm{ON}^{\mathrm{ON}}$. The result that $\mathrm{AWCL}^{\mathrm{ON}}$ is promoted by inputs from AWBR and ASHL, whereas $\mathrm{AWCR}^{\mathrm{ON}}$ has only the cell-autonomous input, is consistent with this.

Side-biased calcium-wave dynamics have been implicated in establishing the left-right axis in vertebrate systems. Intracellular calcium elevation on the left side of the mouse embryonic node, Hensen's node in chick, or zebrafish Kupffer's vesicle is the earliest asymmetric molecular event that is functionally linked to organ laterality (McGrath et al., 2003; Sarmah et al., 2005; GaricStankovic et al., 2008). Calcium may move through gap junctions to reach left side target cells, leading to activation of downstream transcription (Levin and Mercola, 1999; Hatler et al., 2009). In zebrafish, left-sided elevation of intracellular calcium transiently activates CaMKII phosphorylation, which is required for proper left-right organ placement (Francescatto et al., 2010). A similar situation might occur in AWC asymmetry. It is possible that side biases of calcium dynamics in non-AWC cells of the NSY-5 network cause elevation of calcium in one AWC and reduction of calcium in another AWC, leading to increased and decreased CaMKII activity in the future $\mathrm{AWC} \mathrm{OFF}^{\mathrm{F}}$ cell and the future $\mathrm{AWC}^{\mathrm{ON}}$, respectively.

Stochastic cell-fate acquisition in the nervous system is a conserved but only partly understood phenomenon in all species (Johnston and Desplan, 2008; Losick and Desplan, 2008; Johnston and Desplan, 2010). This study suggests a novel mechanism by which stochastic neuronal diversification is established. We propose that stochastic AWC asymmetry is coordinated through competition of different $\mathrm{AWC}^{\mathrm{ON}}$ side biases generated by intracellular calcium signals in non-AWCs of the NSY-5 network, in addition to previously identified intrinsic opposite biases of $n s y$ 4 and $n s y-5$ activity in AWCs (Chuang et al., 2007).

\section{Acknowledgements}

We thank Cori Bargmann for valuable discussions and comments on the manuscript. We also thank David Richards for advice on Fluo-4 calcium imaging; Yan Zou for worm cDNA; Yutaka Yoshida for mouse cDNA; Andy Fire for C. elegans vectors; James Lechleiter (UT Health Science Center, San Antonio, TX) for Parv and ParvCDEF plasmids; the C. elegans Genetic Center for strains; and WormBase.

\section{Funding}

This work was supported by an American Cancer Society Postdoctoral Fellowship [PF-11-028-01-CSM to J.A.S.]; a National Institutes of Health (NIH) Organogenesis Training Grant [to Y.-W.H.]; NIH grants [GM084491 to M.J.A.,
GM077593 to W.-H.L. and R01GM098026 to C.-F.C.]; the March of Dimes Foundation [C.C.]; Whitehall Foundation Research Awards [to C.C. and C.F.C.]; and an Alfred P. Sloan Research Fellowship [C.-F.C.]. Deposited in PMC for release after 12 months.

\section{Competing interests statement}

The authors declare no competing financial interests.

\section{Supplementary material}

Supplementary material available online at

http://dev.biologists.org/lookup/suppl/doi:10.1242/dev.083428/-/DC1

\section{References}

Bargmann, C. I., Hartwieg, E. and Horvitz, H. R. (1993). Odorant-selective genes and neurons mediate olfaction in C. elegans. Cell 74, 515-527.

Bauer Huang, S. L., Saheki, Y., VanHoven, M. K., Torayama, I., Ishihara, T., Katsura, I., van der Linden, A., Sengupta, P. and Bargmann, C. I. (2007) Left-right olfactory asymmetry results from antagonistic functions of voltageactivated calcium channels and the Raw repeat protein OLRN-1 in C. elegans. Neural Dev. 2, 24.

Bennett, M. V. and Zukin, R. S. (2004). Electrical coupling and neuronal synchronization in the mammalian brain. Neuron 41, 495-511.

Blomstrand, F., Khatibi, S., Muyderman, H., Hansson, E., Olsson, T. and Rönnbäck, L. (1999). 5-Hydroxytryptamine and glutamate modulate velocity and extent of intercellular calcium signalling in hippocampal astroglial cells in primary cultures. Neuroscience 88, 1241-1253.

Boitano, S., Dirksen, E. R. and Sanderson, M. J. (1992). Intercellular propagation of calcium waves mediated by inositol trisphosphate. Science $\mathbf{2 5 8}$ 292-295.

Brenner, S. (1974). The genetics of Caenorhabditis elegans. Genetics 77, 71-94. Bui, Y. K. and Sternberg, P. W. (2002). Caenorhabditis elegans inositol 5phosphatase homolog negatively regulates inositol 1,4,5-triphosphate signaling in ovulation. Mol. Biol. Cell 13, 1641-1651.

C. elegans Sequencing Consortium (1998). Genome sequence of the nematode C. elegans: a platform for investigating biology. Science 282, 2012-2018.

Catterall, W. A. (2000). Structure and regulation of voltage-gated Ca2+ channels. Annu. Rev. Cell Dev. Biol. 16, 521-555.

Chang, C., Hsieh, Y. W., Lesch, B. J., Bargmann, C. I. and Chuang, C. F. (2011). Microtubule-based localization of a synaptic calcium-signaling complex is required for left-right neuronal asymmetry in C. elegans. Development 138 3509-3518

Chard, P. S., Bleakman, D., Christakos, S., Fullmer, C. S. and Miller, R. J. (1993). Calcium buffering properties of calbindin D28k and parvalbumin in rat sensory neurones. J. Physiol. 472, 341-357.

Christensen, M., Estevez, A., Yin, X., Fox, R., Morrison, R., McDonnell, M., Gleason, C., Miller, D. M., 3rd and Strange, K. (2002). A primary culture system for functional analysis of $C$. elegans neurons and muscle cells. Neuron 33, 503-514.

Chuang, C. F. and Meyerowitz, E. M. (2000). Specific and heritable genetic interference by double-stranded RNA in Arabidopsis thaliana. Proc. Natl. Acad. Sci. USA 97, 4985-4990.

Chuang, C. F. and Bargmann, C. I. (2005). A Toll-interleukin 1 repeat protein at the synapse specifies asymmetric odorant receptor expression via ASK1 MAPKKK signaling. Genes Dev. 19, 270-281.

Chuang, C. F., Vanhoven, M. K., Fetter, R. D., Verselis, V. K. and Bargmann, C. I. (2007). An innexin-dependent cell network establishes left-right neuronal asymmetry in C. elegans. Cell 129, 787-799.

Clandinin, T. R., DeModena, J. A. and Sternberg, P. W. (1998). Inositol trisphosphate mediates a RAS-independent response to LET-23 receptor tyrosine kinase activation in C. elegans. Cell 92, 523-533.

Dakin, K. and Li, W. H. (2006). Infrared-LAMP: two-photon uncaging and imaging of gap junctional communication in three dimensions. Nat. Methods 3, 959.

Dakin, K., Zhao, Y. and Li, W. H. (2005). LAMP, a new imaging assay of gap junctional communication unveils that $\mathrm{Ca} 2+$ influx inhibits cell coupling. Nat Methods 2, 55-62

Dal Santo, P., Logan, M. A., Chisholm, A. D. and Jorgensen, E. M. (1999). The inositol trisphosphate receptor regulates a 50 -second behavioral rhythm in C. elegans. Cell 98, 757-767.

Davies, A. G., Pierce-Shimomura, J. T., Kim, H., VanHoven, M. K., Thiele, T. R., Bonci, A., Bargmann, C. I. and McIntire, S. L. (2003). A central role of the BK potassium channel in behavioral responses to ethanol in C. elegans. Cell $\mathbf{1 1 5}$ 655-666.

Duerr, J. S., Frisby, D. L., Gaskin, J., Duke, A., Asermely, K., Huddleston, D., Eiden, L. E. and Rand, J. B. (1999). The cat-1 gene of Caenorhabditis elegans encodes a vesicular monoamine transporter required for specific monoaminedependent behaviors. J. Neurosci. 19, 72-84.

Francescatto, L., Rothschild, S. C., Myers, A. L. and Tombes, R. M. (2010). The activation of membrane targeted CaMK-II in the zebrafish Kupffer's vesicle is required for left-right asymmetry. Development 137, 2753-2762. 
Fukumoto, T., Blakely, R. and Levin, M. (2005a). Serotonin transporter function is an early step in left-right patterning in chick and frog embryos. Dev. Neurosci. 27, 349-363.

Fukumoto, T., Kema, I. P. and Levin, M. (2005b). Serotonin signaling is a very early step in patterning of the left-right axis in chick and frog embryos. Curr. Biol. 15, 794-803.

Garic-Stankovic, A., Hernandez, M., Flentke, G. R., Zile, M. H. and Smith, S. M. (2008). A ryanodine receptor-dependent Ca(i)(2+) asymmetry at Hensen's node mediates avian lateral identity. Development 135, 3271-3280.

Grabarek, Z. (2006). Structural basis for diversity of the EF-hand calcium-binding proteins. J. Mol. Biol. 359, 509-525

Harrisingh, M. C., Wu, Y., Lnenicka, G. A. and Nitabach, M. N. (2007). Intracellular Ca2+ regulates free-running circadian clock oscillation in vivo. J. Neurosci. 27, 12489-12499.

Hatler, J. M., Essner, J. J. and Johnson, R. G. (2009). A gap junction connexin is required in the vertebrate left-right organizer. Dev. Biol. 336, 183-191.

Ikura, M. (1996). Calcium binding and conformational response in EF-hand proteins. Trends Biochem. Sci. 21, 14-17.

John, L. M., Mosquera-Caro, M., Camacho, P. and Lechleiter, J. D. (2001). Control of IP(3)-mediated Ca2+ puffs in Xenopus laevis oocytes by the Ca2+binding protein parvalbumin. J. Physiol. 535, 3-16.

Johnston, R. J., Jr and Desplan, C. (2008). Stochastic neuronal cell fate choices. Curr. Opin. Neurobiol. 18, 20-27.

Johnston, R. J., Jr and Desplan, C. (2010). Stochastic mechanisms of cell fate specification that yield random or robust outcomes. Annu. Rev. Cell Dev. Biol. 26, 689-719.

Kandler, K. and Katz, L. C. (1998). Coordination of neuronal activity in developing visual cortex by gap junction-mediated biochemical communication J. Neurosci. 18, 1419-1427.

Kumar, N. M. and Gilula, N. B. (1996). The gap junction communication channel. Cell 84, 381-388.

Lee, S. H., Kim, W. T., Cornell-Bell, A. H. and Sontheimer, H. (1994). Astrocytes exhibit regional specificity in gap-junction coupling. Glia 11, 315-325.

Levin, M. (2007). Gap junctional communication in morphogenesis. Prog. Biophys. Mol. Biol. 94, 186-206.

Levin, M. and Mercola, M. (1999). Gap junction-mediated transfer of left-right patterning signals in the early chick blastoderm is upstream of Shh asymmetry in the node. Development 126, 4703-4714

Levin, M., Buznikov, G. A. and Lauder, J. M. (2006). Of minds and embryos: left-right asymmetry and the serotonergic controls of pre-neural morphogenesis. Dev. Neurosci. 28, 171-185.

Losick, R. and Desplan, C. (2008). Stochasticity and cell fate. Science 320, 65-68. Marsh, K. A. (1995). Single-cell calcium imaging. Methods Mol. Biol. 41, 229-238.

McGrath, J., Somlo, S., Makova, S., Tian, X. and Brueckner, M. (2003). Two populations of node monocilia initiate left-right asymmetry in the mouse. Cell 114, 61-73.

Mello, C. and Fire, A. (1995). DNA transformation. Methods Cell Biol. 48, 451482 .

Pauls, T. L., Durussel, I., Berchtold, M. W. and Cox, J. A. (1994). Inactivation of individual $\mathrm{Ca}(2+)$-binding sites in the paired EF-hand sites of parvalbumin reveals asymmetrical metal-binding properties. Biochemistry 33, 10393-10400.

Peters, J. L., Earnest, B. J., Tjalkens, R. B., Cassone, V. M. and Zoran, M. J. (2005). Modulation of intercellular calcium signaling by melatonin in avian and mammalian astrocytes is brain region-specific. J. Comp. Neurol. 493, 370-380.

Pierce-Shimomura, J. T., Faumont, S., Gaston, M. R., Pearson, B. J. and Lockery, S. R. (2001). The homeobox gene lim-6 is required for distinct chemosensory representations in C. elegans. Nature 410, 694-698.

Roayaie, K., Crump, J. G., Sagasti, A. and Bargmann, C. I. (1998). The G alpha protein ODR-3 mediates olfactory and nociceptive function and controls cilium morphogenesis in C. elegans olfactory neurons. Neuron 20, 55-67.

Sáez, J. C., Connor, J. A., Spray, D. C. and Bennett, M. V. (1989). Hepatocyte gap junctions are permeable to the second messenger, inositol 1,4,5trisphosphate, and to calcium ions. Proc. Natl. Acad. Sci. USA 86, 2708-2712.
Sagasti, A., Hisamoto, N., Hyodo, J., Tanaka-Hino, M., Matsumoto, K. and Bargmann, C. I. (2001). The CaMKII UNC-43 activates the MAPKKK NSY-1 to execute a lateral signaling decision required for asymmetric olfactory neuron fates. Cell 105, 221-232.

Sarmah, B., Latimer, A. J., Appel, B. and Wente, S. R. (2005). Inositol polyphosphates regulate zebrafish left-right asymmetry. Dev. Cell 9, 133-145.

Shaner, N. C., Campbell, R. E., Steinbach, P. A., Giepmans, B. N., Palmer, A. E. and Tsien, R. Y. (2004). Improved monomeric red, orange and yellow fluorescent proteins derived from Discosoma sp. red fluorescent protein. Nat. Biotechnol. 22, 1567-1572.

Shaner, N. C., Steinbach, P. A. and Tsien, R. Y. (2005). A guide to choosing fluorescent proteins. Nat. Methods 2, 905-909.

Sieburth, D., Ch'ng, Q., Dybbs, M., Tavazoie, M., Kennedy, S., Wang, D., Dupuy, D., Rual, J. F., Hill, D. E., Vidal, M. et al. (2005). Systematic analysis of genes required for synapse structure and function. Nature 436, 510-517.

Singer, J. H., Mirotznik, R. R. and Feller, M. B. (2001). Potentiation of L-type calcium channels reveals nonsynaptic mechanisms that correlate spontaneous activity in the developing mammalian retina. J. Neurosci. 21, 8514-8522.

Sze, J. Y., Victor, M., Loer, C., Shi, Y. and Ruvkun, G. (2000). Food and metabolic signalling defects in a Caenorhabditis elegans serotonin-synthesis mutant. Nature 403, 560-564.

Tanaka-Hino, M., Sagasti, A., Hisamoto, N., Kawasaki, M., Nakano, S., Ninomiya-Tsuji, J., Bargmann, C. I. and Matsumoto, K. (2002). SEK-1 MAPKK mediates Ca2+ signaling to determine neuronal asymmetric development in Caenorhabditis elegans. EMBO Rep. 3, 56-62.

Taylor, R. W., Hsieh, Y. W., Gamse, J. T. and Chuang, C. F. (2010). Making a difference together: reciprocal interactions in C. elegans and zebrafish asymmetric neural development. Development 137, 681-691.

Thomas, A. P., Bird, G. S., Hajnóczky, G., Robb-Gaspers, L. D. and Putney, J.

W., Jr (1996). Spatial and temporal aspects of cellular calcium signaling. FASEB J. 10, 1505-1517.

Troemel, E. R., Chou, J. H., Dwyer, N. D., Colbert, H. A. and Bargmann, C. I. (1995). Divergent seven transmembrane receptors are candidate chemosensory receptors in C. elegans. Cell 83, 207-218.

Troemel, E. R., Kimmel, B. E. and Bargmann, C. I. (1997). Reprogramming chemotaxis responses: sensory neurons define olfactory preferences in C. elegans. Cell 91, 161-169.

Troemel, E. R., Sagasti, A. and Bargmann, C. I. (1999). Lateral signaling mediated by axon contact and calcium entry regulates asymmetric odorant receptor expression in C. elegans. Cell 99, 387-398.

VanHoven, M. K., Bauer Huang, S. L., Albin, S. D. and Bargmann, C. I. (2006). The claudin superfamily protein nsy-4 biases lateral signaling to generate left-right asymmetry in C. elegans olfactory neurons. Neuron 51, 291-302.

Wes, P. D. and Bargmann, C. I. (2001). C. elegans odour discrimination requires asymmetric diversity in olfactory neurons. Nature 410, 698-701.

West, A. E., Chen, W. G., Dalva, M. B., Dolmetsch, R. E., Kornhauser, J. M., Shaywitz, A. J., Takasu, M. A., Tao, X. and Greenberg, M. E. (2001). Calcium regulation of neuronal gene expression. Proc. Natl. Acad. Sci. USA 98, 11024-11031.

White, J. G., Southgate, E., Thomson, J. N. and Brenner, S. (1986). The structure of the nervous system of the nematode Caenorhabditis elegans. Philos. Trans. R. Soc. Lond. B 314, 1-340.

Yuste, R., Peinado, A. and Katz, L. C. (1992). Neuronal domains in developing neocortex. Science 257, 665-669.

Yuste, R., Nelson, D. A., Rubin, W. W. and Katz, L. C. (1995). Neuronal domains in developing neocortex: mechanisms of coactivation. Neuron 14, 717.

Zhao, Y., Zheng, Q., Dakin, K., Xu, K., Martinez, M. L. and Li, W. H. (2004). New caged coumarin fluorophores with extraordinary uncaging cross sections suitable for biological imaging applications. J. Am. Chem. Soc. 126, 4653-4663.

Zimmermann, B. and Walz, B. (1999). The mechanism mediating regenerative intercellular Ca2+ waves in the blowfly salivary gland. EMBO J. 18, 3222-3231. 